\title{
Fueling Water-Intensive Economic Growth: What Hope for Water Conservation?
}

\author{
Ola Busari, Jeremiah Mutamba \\ Trans-Caledon Tunnel Authority, Centurion, South Africa \\ Email: obusari@tcta.co.za, jmutamba@tcta.co.za
}

Received 14 July 2015; accepted 22 August 2015; published 25 August 2015

\begin{abstract}
In virtually every country has strategies for pursuing greater broad-based economic growth and fighting poverty and inequality that underscore the pivotal role of water, including its availability in reasonable quantity and desired quality. While GDP growth in South Africa slowed down from $2.2 \%$ in 2013 to $1.5 \%$ in 2014 , and while there are suggestions that current growth drivers are weak and inflation drivers strong, hopes remain for moderate economic growth of upwards of $2.5 \%$ going forward. Aside from stabilizing power supply and securing an upward movement in consumer confidence, such optimism rests on the return of mining and manufacturing activities to their previously high levels, with implications for water requirements. Growing demand for water-intensive growth will be occurring side-by-side with the expanding needs of urbanization and social advancement, in the face of an increasing threat of climate change, recurring droughts, environmental pollution and limited accessible water resources. Effective reconciliation of the demand and supply of water would require the strengthening of water conservation and demand management beyond their currently low to moderate levels, calling for a paradigmatic shift in approaches to water management, sound appreciation of the potential benefits vis-à-vis the allocation of requisite resources and firm political leadership and support.
\end{abstract}

\section{Keywords}

Demand Management, Economic Development, South Africa, Water Conservation

\section{Introduction}

From its currently suppressed GDP growth of $1.5 \%$, South Africa projects to progress into renewed periods of economic performance in the short to medium term. In the frame of the country's long-term development perspective, the 2030 National Development Plan [1], efforts are being intensified to explore alternative paths for inclusive growth and broad-based participation in the economy. Such planning recognizes that water is pivotal to growing the economy, building strong communities and ensuring the well-being of citizens, considering its multi-faceted use in driving agriculture, energy, mining, tourism, urban growth and rural development.

In particular, South Africa's National Infrastructure Plan [2] makes the bold move to prioritize significant resources for the expansion of critical economic and social infrastructure, including that for augmenting water resources to address the strategic requirements of the industrial sector and the troubling electricity sector, as well 
as for developments in mining and agriculture.

The energy sector contributes about $15 \%$ to the country's GDP, and supporting the economic growth targets of the country is linked to closing the gaps in energy and fuel requirements, with the operation of additional plants dependent on huge quantities of water. Mining, a critical destination of the largest foreign investment flows and accounting for about 9\% of GDP, promises to continue to significantly contribute to the economy. But its growing water requirements occur simultaneously with the increasing need to ensure resource protection from pollution from mining activities, and to deal with the complex environmental threat presented by acid mine drainage. Agriculture, while witnessing growing competition for water from industrial and domestic uses, still accounts for the largest water use, receiving nearly $60 \%$ of the country's water resources. Over the full decade leading to 2013 , domestic water use only increased from $22 \%$ to $27 \%$ of the total available water resource [3]. Although the agricultural sector contributes a relatively low 3\% to GDP, the sector provides employment and livelihoods for millions of South African households, especially in rural communities.

Against the backdrop of strategic water infrastructure initiatives, the country is water-scarce and already faces several challenges as a result of the limited and variable nature of its water resources, including the impacts of climate change and environmental pollution [4]. The situation of water scarcity is exacerbated by the geographic mismatch between its relative availability in certain catchments and the centres of strategic industrial activities with the potential to propel economic growth. But also, as [5] argues, the water supply system loses large amounts of water, worsening the pressure on the resource and inflicting supply challenges. Indeed, [6] tracked the level of non-revenue water for urban supply systems across the country during a six-year period, indicating an average of $37 \%$, but pointing to figures as high as $90 \%$ in some municipal water supply schemes.

In a bid to augment and improve water supplies to meet the anticipated demand for socio-economic advancement, water resources planners and managers will more easily opt to continue to turn to supply-driven approaches. Experiences elsewhere, for example [7], suggest that, in several situations, the traditional solution to water problems has been to quickly increase water availability through developing additional sources of water. However, [8] finds that the continued application of traditional water management concepts in contemporary times will not deliver the required results, especially as such approaches would not meet the combined tests of efficiency and cost-effectiveness.

Along similar lines, South Africa's latest National Water Resource Strategy recognizes pointedly that efforts to increase water availability must move beyond conventional engineering approaches to infrastructure development, to emphasize a better mix of reuse of groundwater, rainwater harvesting, desalination and treated acid mine drainage [3]. Also, the genuine pursuit of a sustainable water balance is now strongly acknowledged as requiring renewed and greater attention to water conservation and demand management.

First, this paper provides a global overview of the concept and principles of water conservation and demand management, tracking their application in different settings and summarizing the risks and benefits of efforts to improve application. Second, a review of the experiences in South Africa is presented, including the policy framework and level of actual implementation, so as to identify key constraints and critical success factors, in view of enhancing the hope for better influencing demand and conserving water into the future.

\section{Water Conservation and Demand Management: An Overview}

\subsection{Core Principles}

The principles governing water conservation and demand management (WCDM) are well researched and documented [6] [9] [10]. The principles are predicated on the notion of improving water use efficiency and promoting sustainable use, and their effective application is meant to ensure optimum, long-term, environmentally sustainable social and economic benefit for society [11]. Also, [11] identifies three fundamental principles that underpin WCDM, as follows:

- Water institutions should supply water in an efficient and effective manner by minimizing water losses.

- Consumers should endeavour to use water efficiently.

- WCDM should be considered as part of the planning process for water resources, water supply and sustainable water services.

The foregoing principles emphasize a focus on the reduction of the quantity of water required to accomplish a specific task; adjusting the nature of the task so that it can be accomplished with less water or lower quality water; reduction of losses in movement from source, through use, to disposal; shifting time of use to off-peak pe- 
riods; and increasing the ability of the system to operate during droughts. It is important to note that WCDM principles involve the active participation of all parties in the water value-chain, from the water institutions mandated to manage water resources right down to the end user. Also, as [12] advise, for the principles to make positive impact, there is need for strong support from sound policies and governance.

Universally, conserving water and managing demand are motivated by a number of inter-linked factors. Some of the important drivers are the general lack of new water resources to develop; a growing demand for water supplies to feed economic development, industrial expansion and rising population; diminishing water resources due to continued pollution of the limited resource; and unacceptably high water losses experienced in various uses, including agriculture, communities and municipal centres. Other contributing factors include rapid urbanization and increasing over-exploitation of the groundwater resource [8].

\subsection{Key Measures}

Efforts to conserve water and manage demand at various points in the water value-chain commonly adopt a number of measures. For ease of understanding and application, water practitioners frequently cluster those WCDM measures into certain categories. The four groups summarized by [13] are economic instruments, structural methods, operational procedures and socio-political interventions.

The economic instruments include the use of appropriate pricing policies, block tariff structures, long run marginal costing, cost-benefit analysis techniques and penalties. These approaches are normally deployed to ensure marginal water use is given its real marginal value. Block tariffs are usually applied to ensure that those who use above-average amounts of water pay for the privilege, with the approach of increasing block tariffs a common feature in several countries, including South Africa. The increasing block tariffs achieve two objectives: that of dis-incentivizing high levels of water consumption and that of cross-subsidizing access to minimum levels of use. Economic approaches need to be applied with caution, as they are considered to be the least equitable.

Structural methods emphasize the fitting of on-site pressure reduction devices (retrofitting), the installation of efficient irrigation systems, the adoption of recycling and reclamation systems, segregation of wastewater flows into greywater and sewage, and the use of water efficient devices. Operational procedures focus particularly on pressure reduction measures, leak detection and repairs. Socio-political interventions revolve around the establishment of supportive laws and regulations, including code modifications, as well as the mounting of public awareness programmes on water conservation.

Water utilities are encouraged to use the outlined WCDM measures in combination, as it has been shown that such combination results in the achievement of maximum utility [14]. An example of a possible matrix of generic interventions at different points along the water supply value-chain is presented in Figure 1.

\subsection{Application of the Principles}

Globally, there is a heightened awareness among organizations to improve their water use efficiency and reduce water footprint, as part of sustainability strategies. This consciousness is growing at all levels, regional and national, as well as among manufacturing companies, mining firms and municipal entities. The region of Southern Africa has witnessed the same trend, with governments and organizations demonstrating progress in embracing the principles of WCDM. For example, Zimbabwe and South Africa since introduced new policies and legislation underscoring demand-side management and improved water conservation. Some of the ongoing interventions in Botswana include water tariff reviews, water restrictions and education campaigns seeking to manage water use and water demand. Namibia, in particular, has made significant strides in applying a range of WCDM measures.

As the driest country in sub-Saharan Africa, it is understandable that Namibia would demonstrate the early promotion of an integrated approach to water resource management, combining both supply-oriented and demand-side efficiency measures, especially in its capital city, Windhoek. Windhoek uses treated effluent that applies a dual pipe system for municipal irrigation; water reclamation for potable use was introduced in 1968, with a new plant commissioned in 2002, accounting for $26 \%$ of daily potable supply [15] [16]. In 1994, the city approved an integrated water demand management programme consisting of policy improvements, block tariffs, retrofitting and awareness campaigns, seeking to stimulate efficient water use. The success of integrated WCDM measures resulted in a zero overall growth in water consumption over the period 1990-1997, despite an increase of $35 \%$ in the city's population [15]. 


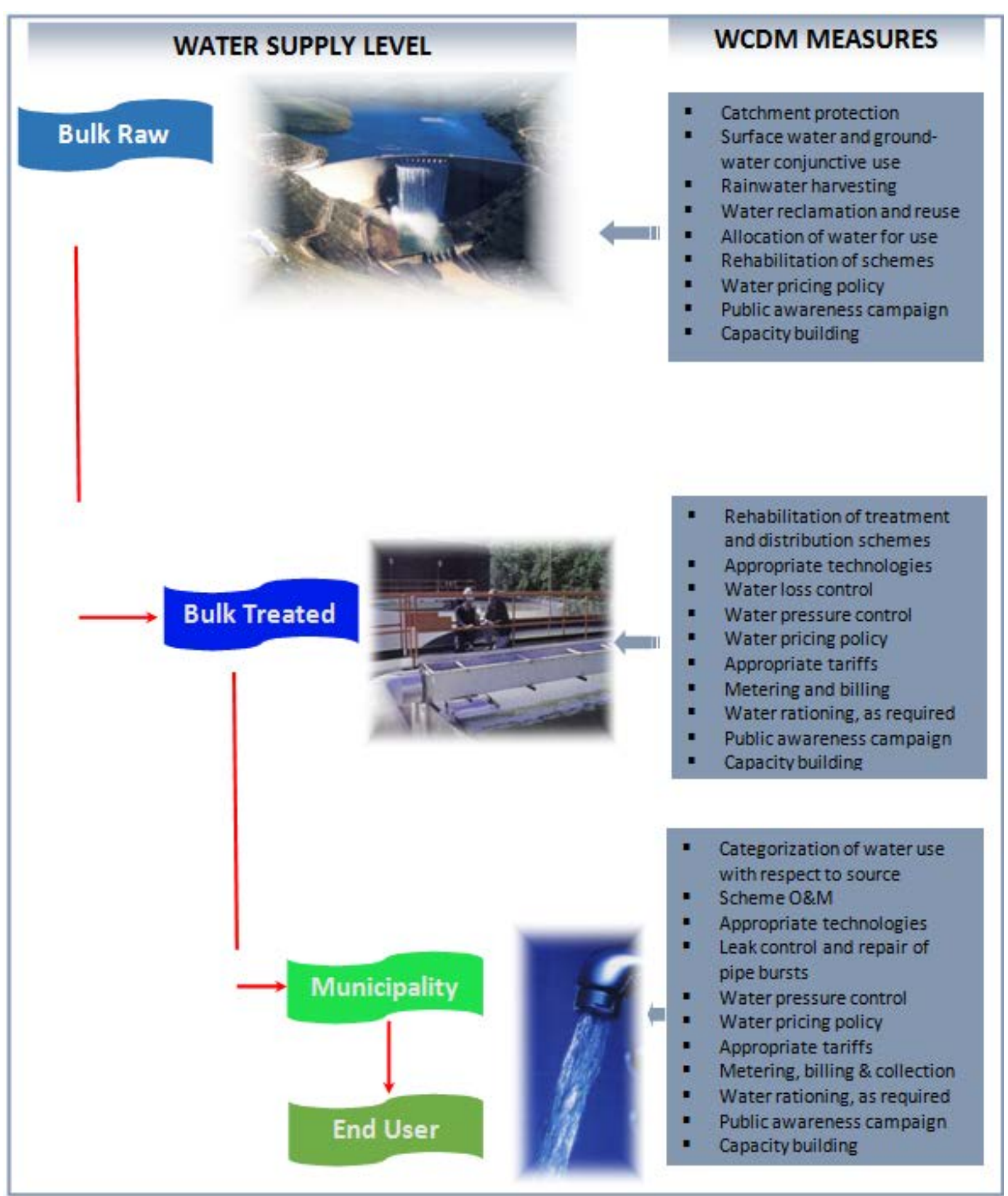

Figure 1. Combination of WCDM measures along the water value-chain.

Across the globe, several cities are known for their innovative programmes on water conservation and demand management. For example, the city of Seattle, USA is reported to have reduced its water consumption by $1 \%$ each year over 23 years, despite an aggregate increase in population of more than $20 \%$ [17]. Also, the city of Athens, Greece aggressively introduced water demand management measures in the 1990s after suffering from severe drought: the mix of strategies implemented included carrying out information campaigns, banning the use of drinking water for other purposes, and adjusting the price of water. Reference [18] reported that, based on the 
level of water consumption in 1989, Athen's initiatives resulted in a 25\% decrease in consumption in 1993 and 35\% reduction in 1995. In Australia, [19] documents the efforts of the Sydney Water Corporation to manage demand as centering on expanded water reuse and rainwater harvesting, as well as retrofitting, pricing reform and awareness campaign.

There are also many applications of WCDM measures at the industrial level. Reference [20] captures the interventions of a German fruit packaging company, Dole Europe, focusing on four areas of water efficiency: maximization of rainwater use, implementation of advanced irrigation techniques, optimization of the water used during the packing process, and special attention to the quality of return water. The results suggest that Dole managed to reduce its water use per unit of production. For example, it is reported that Dole used around 100 litres of water to produce one kilogram of Dole pineapples, and about 250 litres for a kilogram of Dole bananas. Reference [20] juxtaposes its water use with a global average of around 1600 litres of water used for the production of one kilogram of plums, 3000 litres of water for one kilogram of rice and about 15,000 litres of water for one kilogram of beef.

Examples of businesses aggressively looking for opportunities to improve their water use efficiency through WCDM measures are commonplace, with some launching ambitious global water conservation programmes and many other setting targets of reducing water use in corporate buildings through the installation of low-flow toilet systems, urinals and sinks. It is now common knowledge that conserving and saving water is critical for continued global business development and sustainability.

\subsection{Risks and Benefits}

Several advantages and benefits can be derived from the dedicated and successful application of the principles underpinning water conservation and demand management. Reference [15] identifies a number of such benefits, as follows:

- More efficient use of existing water supplies.

- Reduction in water leakage and promotion of the equitable use of water.

- Deferment of additional spending on water and wastewater infrastructure.

- Cost savings to water users, as a result of paying only for water received rather than for water lost in the distribution system, as well as cost savings for bulk water suppliers due to a reduction in the amount of water that would be purchased.

- Promotion of environmental quality improvements and integrity through the lowering of water losses and unwarranted development of large infrastructure.

- Energy savings through the deferment of huge pumping facilities associated with large water transfer schemes.

- Reduction in supply disruptions to water users, arising from frequent bursts and repairs.

- Improvements in water quality through the lessening of pollution of water resources.

- Increased revenues from previously undercharged customers and formerly illegal and previously un-paying customers.

- Better management of future water uses and certainty in water demand forecasts.

- Lowering of the financial risk of miscalculating demand far into the future.

- Water saving technologies are not usually capital-intensive, thus they can be implemented at affordable cost.

- Opportunity to build water management databases and to develop water balances, as appropriate implementation requires the measurement of all components of the water cycle.

- Expanded knowledge of the water distribution system, as well as of the water system in general.

- High benefit-to-cost ratios in excess of 10:1 in several urban situations.

In spite of the numerous advantages, carrying out demand-side management and conservation faces certain risks and challenges that water practitioners should take cognizance of and plan mitigation measures for. In particular, once significant efforts have been expended implementing the applicable measures, it may be difficult to sustain the levels of water loss reduction achieved. It needs to be understood that WCDM is not a once-off initiative, but rather an ongoing exercise that should form part of the water management process for water institutions. In order to sustain the achieved levels of gains, it is important to continuously dedicate a competent team and appropriate budget to the program.

Further, WCDM should be considered as a participatory process requiring the interwoven and complex in- 
volvement of an array of stakeholder groups. At times, the stakeholders are not willing or available to participate in the process-which jeopardizes the chances of success. There is also a risk of implementing sub-optimal strategies, a frequent occurrence where limited budgets are made available to tackle huge challenges.

\section{The South African Setting}

\subsection{Legal and Policy Framework}

Water management in South Africa is regulated primarily through two pieces of legislation - the National Water Act of 1998 and the Water Services Act of 1997. Both Acts prescribe several requirements and provisions for the implementation of strategies for water conservation and demand management. Importantly, the Constitution of South Africa affirms the right of all citizens to a healthy living environment, including access to adequate and affordable water services. In this vein, government introduced a Free Basic Water policy in 2000, to facilitate sustainable access to a basic water supply by subsidizing the ongoing operation and maintenance costs of a basic service.

Direct responsibility for the provision of water services was vested in local government, with anticipated backstopping by provincial and national government. In response to new municipal legislation, the Strategic Framework for Water Services was approved by Cabinet in 2003, updating national policy on water services and, notably, effectively revising the provisions of the 1997 Water Services Act [21].

The Water Services Act requires water services institutions to establish modalities for the supply of water that prioritize the promotion of demand-side management and conservation. Also, the Act makes provision for the Minister of Water and Sanitation to prescribe compulsory national standards relating to the effective and sustainable use of water resources. On its part, the Strategic Framework for Water Services points to the scarcity of water resources in South Africa and underscores that due attention is paid to water conservation and demand management. In particular, the framework requires water services institutions to develop appropriate water conservation and demand management strategies, which should be reflected in their water services development plans.

The National Water Act provides for the development of a National Water Resources Strategy, first published in 2004 and revised in 2013, as a comprehensive tool for managing water resources throughout the country. More specifically, South Africa also adopted a National Water Conservation and Demand Management Strategy, emphasizing the critical elements and requirements for effective implementation across several sectors, including industry, mining and power generation, agriculture, forestry and water services.

\subsection{Implementation Initiatives}

Until the mid-1990s, the approach to water resources planning and management in South Africa was predominantly traditional, focusing on the supply-side assessment and development of the resource [15], with extensive investment in medium to large-scale storage dams and water transfer infrastructure feeding growth regions experiencing water deficits. As part of the broad sector reform of the post-1994 democratic dispensation, the new government launched a National Water Conservation Campaign, signifying a shift towards more holistic approaches to water management.

The national initiative was designed and driven against the background of the international perspective that efforts to conserve water and manage demand were more likely to succeed when the measures introduced were multi-pronged and simultaneous, incorporating technological, economic and socio-political dimensions. Several projects, 56 in all, were identified for implementation across all major water use sectors, spanning agricultural, municipal, industrial, mining, power generation and environmental. The scale of the program left little room for prioritization and effective coordination, affecting the achievement of meaningful results. Commitment to the roadmap already charted in the 1994 national conservation campaign was reinforced with the reform of the policy and legislative setting for the fast-tracking of water services and the broader management of water resources, as described in the foregoing section.

Yet, as [22] argues, in spite of the mainstreaming of measures to conserve water and manage demand into national policies and regulations, actual implementation progress remains inadequate. There is agreement that South Africa still loses plenty of water through theft, leakages and frequent pipe bursts as a result of ageing infrastructure, and a recent study by [6] documents an average proportion of non-revenue water of $37 \%$, reaching 
a very high $90 \%$ in some municipal areas. Reference [6] particularly reports that, notwithstanding the setting of clear targets to reduce water loss by $50 \%$ by 2014 , the carry-through of the appropriate interventions at the municipal level has been rather limited. Reference [10] believes that the insufficient attention to implementation in municipal water supplies may be related to lack of appreciation of the implications and potential benefits of WCDM.

\subsection{Constraints to Implementation}

It is worthy of note that the foregoing trend of muted implementation of demand-side management and conservation is not unique to South Africa: Several workers report that, while the concept and principles are well understood and embraced, limited application in practice is widespread [12] [23]-[26]. The main constraints to wider application, beyond the progress in policy reform, include the following:

- Political support and leadership: In juxtaposition with the more visible development of new water supply sources, such as the construction of dams and large-scale transfer schemes, demand-side programs and conservation initiatives are not very popular with political heavyweights, as they are generally viewed as software and, therefore, low-impact, interventions.

- Attitude and awareness: There is a low awareness of the value of water, partly because of the perception of its natural availability and/or accessibility in some form for some use, and partly due to the consideration of water as a public good, with government-subsidized supply free of charge to rural households and indigent residents in urban centres. In several places, the interest of stakeholders in actively participating in mounted initiatives is weak, and encouraging willingness by stakeholders is often a slow process.

- Institutional capacity: Implementing agents frequently point to weaknesses in their capacity to roll-out welldesigned programs, including the requisite technical and managerial skills, as well as financial resources, for sustaining and tracking the interventions.

Moving water conservation and demand management into greater adoption in programmatic improvements, from its current broad-based theoretical appeal, would require that more concerted efforts be devoted to tackling the aforementioned impediments.

\section{Conclusions}

Now and into the future, managing water smartly is critical to sustainably fueling economic growth and driving social development across South Africa. Conventional supply-oriented management approaches have proved inadequate for addressing the yawning disparity between available resources and the expanding, competing water requirements. While the need for demand-side management and conservation is well understood and widely embraced with fruitful application growing in some countries and industries, the level of implementation in several developing countries, including South Africa, remains low to moderate.

Critical elements required for the successful implementation of water conservation and demand management are two-fold. The first relates to the need for the high-level political buy-in and stewardship that would lead to an effective paradigmatic shift for taking initiatives into implementation, as well as, ultimately, for going to scale. The second calls for the allocation of sufficient resources on an ongoing basis, including born-again water managers with the capacity to ensure that planning is not only integrated but inclusive, and that it is followed by careful implementation.

\section{References}

[1] National Planning Commission (2013) National Development Plan 2030: Our Future, Make it Work. National Planning Commission, Government of South Africa, Pretoria.

[2] PICC (2012) A Summary of the South African National Infrastructure Plan. Presidential Infrastructure Coordinating Commission, Government of South Africa, Pretoria.

[3] DWA (2013) National Water Resource Strategy: Water for an Equitable and Sustainable Future. Department of Water Affairs, Government of South Africa, Pretoria.

[4] Busari, O. and Ndlovu, J. (2012) Leveraging Water Infrastructure for Transformative Socio-Economic Development in South Africa. WIT Transactions on Ecology and the Environment, 162, 435-446. http://dx.doi.org/10.2495/EID120381

[5] Mutamba, J. and Busari, O. (2014) Strategic Coordination for Sustainable Investment in Critical Infrastructure. Journal of Geoscience and Environment Protection, 2, 79-86. http://dx.doi.org/10.4236/gep.2014.25011 
[6] McKenzie, R.S., Siqalaba, Z.N. and Wegelin, W.A. (2012) The State of Non-Revenue Water in South Africa. Research Report WRC-TT-522/12, Water Research Commission, Pretoria.

[7] Gumbo, B. and van der Zaag, P. (2002) Water Losses and Political Constraints to Demand Management: The Case of the City of Mutare. Physics and Chemistry of the Earth, 27, 805-813. http://dx.doi.org/10.1016/S1474-7065(02)00069-4

[8] Kayaga, S. and Smout, I. (2008) Water Demand Management: A Key Building Block for Integrated Resource Planning for the City of the Future. Annual Conference of Allied Social Sciences Association, New Orleans, 4-6 January.

[9] McKenzie, R.S. and Bhagwan, J.N. (2000) Managing Unaccounted for Water in Potable Water Distribution Systems: Recent Software Developments through the WRC. Journal of the Institution of Municipal Engineers, January, 53-58.

[10] Wegelin, W.A. and Jacobs, H.E. (2013) The Development of a Municipal Water Conservation and Demand Management Strategy and Business Plan as required by the Water Services Act, South Africa. Water SA, 39, 415-422. http://dx.doi.org/10.4314/wsa.v39i3.11

[11] DWAF (2004) National Water Conservation and Demand Management. Department of Water Affairs and Forestry. Government of South Africa, Pretoria.

[12] Mohapatra, S.P. and Mitchell, A. (2009) Groundwater Demand Management in the Great Lakes Basin-Directions for New Policies. Water Resources Management, 23, 457-475. http://dx.doi.org/10.1007/s11269-008-9283-3

[13] UNCHS (1989) The Conservation of Drinking Water Supplies: Techniques for Low-income Settlements. United Nations Centre for Human Settlements, Habitat, Nairobi.

[14] Pansegrouw, J.P. (2005) Water Demand Management-Current Water Productivity Methodology and Water Management Tool in South Africa. Conference Series Papers, International Water Management Institute.

[15] Herbertson, P.W. and Tate, E.L. (2001) Tools for Water Use and Demand Management in South Africa. Technical Reports in Hydrology and Water Resources \#73, World Meteorological Organization, Geneva.

[16] Lahnsteiner, J. and Lempert, G. (2007) Water Management in Windhoek, Namibia. Water Science \& Technology, 55, 441-448. http://dx.doi.org/10.2166/wst.2007.022

[17] US-EPA (2002) Cases in Water Conservation: How Efficiency Programs Help Water Utilities Save Water and Avoid Costs. United States Environmental protection Agency, Washington DC.

[18] Kampragou, E., Lekkasb, D.F. and Assimacopoulos, D (2009) Water Demand Management: Implementation Principles and Indicative Success Stories. http://www.samos.aegean.gr/actuar/dlekkas/cv/

[19] White, S. (2001) Demand Management and Integrated Resource Planning in Australia. Paper Presented at the Conference on Efficient Use and Management of Water for Urban Supply, Madrid.

[20] Dole (2011) Corporate Responsibility and Sustainability. Dole Food Company Newsletter, 1.

[21] Busari, O. and Jackson, B. (2006) Reinforcing Water and Sanitation Sector Reform in South Africa. Water Policy, 8, 303-312. http://dx.doi.org/10.2166/wp.2006.038

[22] Mwiinga, G., Gumbo, T. and Mkoka, I. (2008) Water Conservation and Demand Management in Practice: South Africa Case Studies. Paper Presented at the WISA Conference, Sun City.

[23] Stiles, G. (1996) Demand-Side Management, Conservation and Efficiency in Use of Africa's Water Resources. In: Rached, E., Rathgeber, E. and Brooks, D., Eds., Water Management in Africa and the Middle East: Challenges and Opportunities, IDRC Books, Ottawa.

[24] Arlosoroff, S. (1998) Water Demand Management. UNCHS (Habitat) Regional Conference on Sustainable Consumption Patterns in Asian Cities, Fukuoka, 29 June-1 July 1998. http://www.fukuoka.unchs.org/english/information/Occassional/water-e.html

[25] Mwendera, E.J., Hazelton, D., Nkhuwa, D., Robinson, P., Tjijenda, K. and Chavula, G. (2004) Overcoming Constraints to the Implementation of Water Demand Management in Southern Africa. Physics and Chemistry of the Earth, 28, 761-778. http://dx.doi.org/10.1016/j.pce.2003.08.002

[26] Mutamba, J. and Busari, O. (2012) Municipal Lessons in Water Demand Management: Case Study from South Africa. Proceedings of 34th Hydrology and Water Resources Symposium, Sydney, 1385-1392. 